\title{
Exploring Personal Development Workshops' Effect on Well-being and Interconnectedness
}

\author{
Helané Wahbeh ( $\nabla$ hwahbeh@noetic.org ) \\ Institute of Noetic Sciences \\ Garret Yount \\ Institute of Noetic Sciences \\ Cassandra Vieten \\ Institute of Noetic Sciences \\ Dean Radin \\ Institute of Noetic Sciences \\ Arnaud Delorme \\ Institute of Noetic Sciences
}

\section{Research Article}

Keywords: workshop, wellness programs, well-being, interconnectedness, meditation, personal development

Posted Date: September 9th, 2021

DOI: https://doi.org/10.21203/rs.3.rs-301757/v2

License: (c) (i) This work is licensed under a Creative Commons Attribution 4.0 International License. Read Full License

Version of Record: A version of this preprint was published at Journal of Integrative and Complementary Medicine on January 1st, 2022. See the published version at https://doi.org/10.1089/jicm.2021.0043. 


\section{Abstract}

Introduction: Personal development workshops are increasingly popular. This study evaluated the relationships between measures of well-being, interconnectedness, and extended perception in various workshops and explored which kinds of workshops and individual characteristics predicted changes in these outcomes.

Materials and Methods: In a prospective, uncontrolled, within-participant design study, adult participants completed questionnaires and online tasks before and after personal development workshops. Three analyses were conducted: 1) examining the relationships between measures using only preworkshop measures using Spearman correlations; 2) exploring change scores pre- to post-workshop and workshop using Wilcoxon signed-rank test; 3 ) assessing workshop format and content, and individual characteristics as predictors of those change scores multivariate nonparametric regression. The following outcomes were collected: Well-being - Arizona Integrative Outcomes Scale, positive and negative affect, Dispositional Positive Emotions Scale Compassion subscale, Sleep Quality Scale, Numeric Pain Rating Scale; Interconnectedness - Cloninger Self-Transcendence Scale, Inclusion of Nature in Self and Inclusion of the Other in Self; and Extended perception tasks - Intuition Jar, Quick Remote Viewing, Psychokinesis Bubble, and Time Estimation. The following potential predictor variables were collected: demographic, mental health, psychiatric and meditation history, Single General Self-Rated Health Question, Brief Five-Factor Inventory - 10, and the Noetic Experience and Belief Scale. Workshop leaders also selected which format and content characteristics applied to their workshop.

Results: Interconnectedness measures were significantly and positively correlated with well-being ( $\rho: 0.27$ to 0.33 ), positive affect ( $\rho: 0.20$ to 0.27 ), and compassion ( $\rho: 0.21$ to 0.32 ), and negatively correlated with sleep disturbance ( $\rho:-0.13$ to -0.16 ) and pain ( $\rho:-0.11$ to -0.16$)$. Extended perception task performance was not correlated with interconnectedness or well-being. General personal development workshops improved subjective interconnectedness, well-being, positive emotion, compassion, and reduced sleep disturbances, negative emotion, and pain (all $p$ 's $<0.00005)$. The lecture $(p=0.03)$, small groups $(p=0.001)$, pairs $(p=0.01)$, and discussion $(p=0.03)$ workshop formats were significant predictors of well-being outcomes. The workshop content categories of meditation $(p=0.0002)$ and technology tools $(p=0.01)$ were also predictive of well-being outcomes, with meditation being the most consistent predictor of positive well-being changes. Conscientiousness was the only significant individual characteristic predictor $(p=$ 0.002), although it was associated with increases in some well-being measures and decreases in others.

Conclusions: This study provides preliminary evidence for the positive relationship between the subjective sense of interconnectedness and multiple wellbeing measures and the beneficial effects of some personal development workshops.

\section{Introduction}

The global personal growth market was valued at $\$ 38.28$ billion in 2019 , reflecting its increasing popularity. It is expected to grow an additional $5 \%$ from 2020 to $2027 .{ }^{1}$ Online programs were already on the rise, but with COVID-19, virtual programs became ubiquitous for just about any topic. People seek personal growth opportunities for many reasons, such as improving well-being, feeling connected to themselves and others, and experiencing transpersonal or transcendent states.

Much research has been conducted on well-being and how to measure it. Well-being definitions vary, but most include a person's reflective assessment of their life, emotional states, and a sense of meaning and purpose in life. ${ }^{2}$ The relationship between a subjective sense of happiness and living a meaningful and purposeful life, with physical health, mental health, and even mortality, is well established. ${ }^{3}$ Part of our sense of well-being may stem from our sense of interconnectedness with people and the larger world around us. Interconnectedness has been associated with peace of mind, mental well-being, civic engagement, and humanitarianism. ${ }^{4}$

People experience interconnectedness in many ways. Transcendent states are commonly reported in contemplative and spiritual practice traditions worldwide. Across traditions, the state is described similarly as a relaxed wakeful state of awareness free from mental content, usually accompanied by a feeling of bliss, and subjectively experienced in a phenomenologically different space-time than that experienced in everyday life. A systematic review evaluated the physiological similarities of people experiencing this state in laboratory meditation studies. ${ }^{5}$ A unique physiological signature emerged in that review, with slowed breathing and respiratory suspension being the most robust finding reflecting the subjectively interconnected state. Some people report extraordinary perceptual experiences during or following such meditation, such as knowing something will happen before it does, "seeing" things that happen at a distance, or increased intuition and synchronicities. ${ }^{6,7}$ Some of these extended perceptions can also be reliably observed in laboratory and real-world settings: psychokinesis or mind-matter interactions, ${ }^{8,9}$ distant healing intention effects, ${ }^{10-12}$ remote viewing, ${ }^{13}$ and precognition (the ability to know something that has not yet happened). ${ }^{14-16}$ The subjective experience of interconnectedness may involve the awareness of a previously unknown aspect of physical reality, leading to extended perception not limited by conventional notions of space and time.

While the concepts of well-being, interconnectedness, and extended perception may appear disparate, we hypothesize that they are related. Observing these relationships in the context of personal development may provide a greater understanding of these topics. Few formal studies have evaluated these concepts' relationships to date, such as correlation studies of extended perception and well-being. ${ }^{17-19}$ More research is needed.

This study's primary goal was to investigate the relationship between these three factors: well-being, interconnectedness, and extended perception. Secondary goals were to explore optimal measures, evaluate effects, and conduct power calculations for assessing the influence of transformational practices and individual characteristics on those relationships. This exploratory study thus used a prospective, uncontrolled, within-participant design. 
Participants were invited to complete questionnaires and tasks before and after low-risk personal development workshops, retreats, or courses conducted in-person or online. The study's objectives were to evaluate three research questions: 1) What are the relationships, if any, between measures of wellbeing, interconnectedness, and extended perception? 2) What measure changes, if any, occur from before to after the workshops? and 3 ) What workshop and individual characteristics, if any, predict changes in outcomes? Data from this study will be used to evaluate preliminary effects and conduct power calculations for a future formal study evaluating these three research questions.

\section{Materials And Methods}

\section{Participants}

Inclusion criteria: Participants aged 18 years or older who could read and understand the consent form and complete the survey and tasks, and who had access to the survey online or at the Institute of Noetic Sciences (IONS) EarthRise Learning Center (Petaluma, California, USA). Exclusion criteria: People younger than 18 years of age, inability to understand the consent form, or acute or chronic illness that precluded completion of measurements. No predetermined sample size was calculated for this study because no previous study has evaluated the three research questions. Data collected in this study is being used for sample size calculations for future trials.

\section{Recruitment}

Participants were recruited through the IONS webpage dedicated to the IONS Discovery Laboratory (IDL) research program, where potential workshop leaders learned about the opportunity. In addition, workshop leaders and individuals visiting the campus learned about the program from the IONS EarthRise Learning Center reservations department. Postcards, flyers, the IONS blog, and newsletters were distributed to community networks, previous workshop leaders, and conferences and meetings. All study activities were approved by the IONS Institutional Review Board (approval designation WAHH_2018_01).

\section{Study Procedures}

Participants included in the analyses completed either one survey before an event or two surveys, one before (pre-survey) and one after the event (postsurvey). Not all participants were invited to complete a post-survey for various reasons. For example, some participants were part of a psychology course and wanted to experience being a research participant. Other participants were being evaluated at our laboratory for physiology studies and were not part of a workshop. Other participants were part of another experiment (not a workshop) that did not lend itself to a post-survey. Furthermore, some participants who did participate in a workshop choose not to complete a pre-survey or post-survey. Participants who only completed a pre-survey were included in the analysis for research question 1, evaluating the relationships between the three factors, because the cross-sectional correlation analysis did not need the post-survey data. Participants who completed pre- and post-surveys were included in the analysis for questions 2 and 3 . Please see Figure 1 or a schematic of participants.

Volunteers received an IDL survey link to complete before their workshop or course. The survey could be completed on any computer with access to the internet. They entered their first name and date of birth, which generated an anonymized ID. Volunteers acknowledged that they read and understood the consent form and agreed to participate before continuing the survey. Then they completed a series of online tasks and self-report questionnaires measuring interconnectedness, extended perceptions, and well-being (see Measures below and Supplemental Data).

After completing the pre-survey, participants engaged in their workshop or course. These events varied in duration and content (e.g., meditation retreats, sound healing, energy medicine). Some but not all participants completed the post-survey after their event. Participants were advised to complete the survey as close as possible to the workshop's beginning and ending. The time of participant survey completion varied due to travel to and from the workshop site and other uncontrollable variables. Participants who completed the survey on-site were also invited to provide two minutes of resting four-channel electroencephalography (EEG) and one lead electrocardiography (ECG) data collection (these data are presented elsewhere).

\section{Measures}

Detailed measure descriptions are available in the Supplemental Data. The well-being measures included the Arizona Integrative Outcomes Scale (AIOS; overall well-being), ${ }^{20}$ positive and negative affect (PA, NA), ${ }^{21}$ Dispositional Positive Emotions Scale - Compassion subscale (Comp), ${ }^{22}$ Sleep Quality Scale for sleep disturbance (SIp-24), ${ }^{23}$ and Numeric Pain Rating Scale for pain over the last 24 hours (Pn-24). ${ }^{24}$ Subjective interconnectedness was measured with the Cloninger Self-Transcendence Scale (Int) ${ }_{1}{ }^{25}$ Inclusion of Nature in Self (Int Nature), ${ }^{26,27}$ and Inclusion of the Other in Self (Int Others). ${ }^{28,29}$ Extended perception assessment included four tasks designed to measure: intuition or hunches (Jar Task-Intuition), precognition (Quick Remote Viewing Task-RV), psychokinesis (Bubble Task), and Time Estimation (alterations in subjective time-Time). The following variables were collected to describe participant characteristics and potential predictors: demographic variables, mental health, and psychiatric history, meditation history, Single General SelfRated Health Question ${ }^{30}$ (general health), Brief Five-Factor Inventory - 10 (personality), ${ }^{31}$ and the Noetic Experience and Belief Scale. ${ }^{32}$ Workshop leaders were also asked to rate the format and content topics of their offerings. 


\section{Statistical Analysis}

The following analyses were completed to answer the three research questions.

Research Question 1. What are the relationships, if any, between measures of well-being, interconnectedness, and extended perception? Spearman's rank correlation tests were utilized because the measures were not normally distributed (Shapiro-Wilk $p<0.05)$. Only pre-event surveys were analyzed for correlations among measures. Only the first pre-survey was used for people who participated in multiple workshops.

Research Question 2: What measures demonstrate significant pre-post measure changes? These analyses used a dataset with participants' paired data (i.e., participants completed a survey before and after their workshop). Differences of pre- and post-scores for each measure were evaluated using the Wilcoxon signed-rank test since data were not normally distributed (Shapiro-Wilk $\mathrm{p}>0.05$ ).

Research Question 3: What workshop or individual characteristics, if any, predict changes in outcomes? Change scores were calculated and used in the regression analyses. The analyses to explore which workshop and individual characteristics may predict outcome changes used Nonparametric multivariate regressions with the R package Multivariate Nonparametric Methods. ${ }^{33}$ The MNM uses score tests to determine explanatory variables' effects on response outcomes. Explanatory variable sets were 1) workshop format, 2) workshop content, 3) demographic variables, and 4) mental and physical health. Response variable sets were 1) well-being, 2) interconnectedness, and 3) extended perception. Thus, 12 models were examined. Each model was fit on complete cases (i.e., that were not missing response and explanatory variables). Score tests were performed by comparing the full model with a reduced model generated by removing one explanatory variable.

Categorical variables are described with counts and percentages, continuous variables with means and standard deviations. Participants were not required to complete every item in the survey. Thus, participant numbers are not equal for each variable and are listed with relevant analyses in the results section. Multiple comparison corrections were conducted for all analyses with the False Discovery Rate ${ }^{34}$ (with alpha set to $p<0.05$ ) to establish a cut-off $p$-value for significance. The $p$-values presented are the uncorrected values. Statistical analyses were conducted using Stata 15.0 (StataCorp, LLC, Texas) and R (R Core Team, 2019).

\section{Results}

\section{Included Data}

There were 1898 records collected from March 17, 2018, to November 4, 2020. Two datasets were created to answer the three research questions. The first dataset consisted of unique participants who completed the pre-survey for the correlation analysis of research question 1 . No post-survey responses are used in this cross-sectional analysis, and thus, the maximally usable records were included. Of the 1898 records, 1175 were unique pre-event records. The following were excluded from this dataset: 1) 56 records were pre-surveys from people who had multiple records of the pre-survey (non-unique participants); 2) 106 records were from post-surveys without a matching pre-survey; 3) 27 records were third, fourth or fifth administrations for workshops that had multiple programs throughout the year. In these cases, only the first and second surveys were included; and 4) 534 post-surveys were completed that had matching pre-surveys (see Figure 1). A second dataset consisting of the 534 matching pre- and post-surveys was used to analyze research questions 2 and 3 .

\section{Participant Characteristics}

Participant characteristics for both datasets are displayed in Table 1. Participants hailed mostly from the United States (1033, $88 \%$ ), followed by Canada (48, 4\%) and United Kingdom (16, 1.4\%), Australia (12;1.0\%), and the remaining countries with less than 1\% each: Austria, Brazil, China, Dominican Republic, France Germany, Indonesia, Ireland, Israel, Jordan, Mauritius, Mexico, Netherlands, Oman, Portugal, Singapore, South Africa, Spain, Switzerland, Turkey, Uganda, and United Arab Emirates. For all the unique individuals, participants reported attending $2.5 \pm 2.8$ workshops $(\mathrm{N}=1146)$ within the last year, and in their lifetime, $22.6 \pm 27.8(\mathrm{~N}=1144)$.

\section{Research Question 1: What are the relationships, if any, between measures of well-being, interconnectedness, and extended perception?}

The means, standard deviations, and Spearman rank correlations are displayed in Table 2. The False Discovery Rate multiple comparison correction level of significance was $p=0.043$. There were 34 significant correlations at this level, 29 of which were significant at the $p<0.00005$ level.

The interconnectedness measures were moderately correlated ( $\rho=0.35$ to 0.43 ). Intuition (Jar Task) was weakly correlated with the variable "interconnectedness with others." No other extended perception measure was significantly correlated with any other measures. Interconnectedness measures were significantly and positively correlated with well-being ( $\rho: 0.27$ to 0.33 ), positive affect ( $\rho: 0.20$ to 0.27 ), and compassion ( $\rho$ : 0.21 to 0.32 ), and negatively correlated with sleep disturbance ( $\rho:-0.13$ to -0.16 ) and pain ( $\rho$ : -0.11 to -0.16$)$. The well-being measures were all significantly correlated with each other at varying strengths except for compassion with negative affect and sleep disturbance (Table 2).

Research Question 2: What Measures Demonstrate Significant Pre-Post Measure Changes? 
There were 534 paired pre-post records, with 11 people taking more than one workshop (10 completed two, and one person completed three). For the various reasons mentioned in the methods section, six hundred forty-one people did not have a post-event record and were not included in this dataset. Participant demographics for the paired pre-post dataset are displayed in Table 1. In addition, participants rated their sleep disturbance $4.2 \pm 2.5$ ( $\mathrm{n}-503$ ) and pain $3.8 \pm 2.6$ (n-509) over the last month and their lifetime mental health diagnoses. Two hundred forty-one lifetime mental health diagnoses were endorsed in 152 people (they could check all that applied): including mania (n-77), anxiety disorder ( $\mathrm{n}-72)$, posttraumatic stress disorder ( $\mathrm{n}-50)$, substance dependence requiring treatment (n-24), bipolar disorder ( $\mathrm{n}-13)$, and psychosis or schizophrenia ( $\mathrm{n}-1)$. Seventy-six participants said they were currently being treated for a psychiatric condition with medication, psychotherapy, both, or some other form of treatment. Five-factor personality variables included Extraversion $3.2 \pm 1.0$ (n-514), Agreeableness $3.6 \pm 0.9$ (n-514), Conscientiousness $4.1 \pm 0.8$ ( $n-514$ ), Neuroticism $2.8 \pm 1.0$ ( $n-512$ ), Openness 3.8 \pm 0.9 (n-515). Their noetic belief was $78.8 \pm 18.7$ ( $n-510)$, and noetic experience was $55.5 \pm 22.5(n-509)$.

There were 33 different workshops represented in the dataset. Workshop leaders checked on the interest form that they used the following format types in their workshops: lecture (n-22), small group (19), pairs (n-12), discussion (n-17), movement ( $\mathrm{n}-10)$, and outside/in nature (n-9). They also endorsed the following content categories: meditation ( $n-17)$, positive psychology ( $n-17)$, spirituality ( $n-13)$, health and healing (n-12), intention ( $n-12)$, intuition ( $n-11)$, nature practices (n-10), embodied practices (n-9), art (n-7), death and dying (n-5), sound healing ( $n-5)$, parapsychology (n-4), technology tools ( $n-4)$, altered states of consciousness ( $n-1)$, and dreamwork ( $n-1)$. The last two workshop content variables were not included in the predictor analysis because only one workshop included that content. Please note that the workshop leaders could check more than one content type when describing their workshop, and the exclusion of these two workshop content variables did not result in any workshops being excluded from the analyses. The average time between the pre- and post-surveys completion was $34.0 \pm 45.5$ days (range 0.08 to 319.8 days), which reflected the workshops varying lengths from as short as two hours to as long as ten months.

Participants reported previously attending $2.4 \pm 2.8$ workshops $(n-510)$ in the last year and $22.9 \pm 27.7$ ( $n-508)$ in their lifetime. Participants reported reasons for attending their current workshop, including personal growth ( $n-519)$, spiritual (n-350), business ( $n-248)$, academic ( $n-85)$, and rest and relaxation (n-82). Fifty participants $(9.5 \%)$ said they began the pre-survey after workshop activities had begun.

The means, standard deviations, and pre-post comparisons combining all the workshops are displayed in Table 3. Overall well-being, positive emotion, and compassion significantly increased, and negative emotion, sleep disturbance, and pain significantly decreased. All three interconnectedness measures significantly improved. The remote viewing task results were significantly different after the workshops. The remote viewing task asks participants to choose which of five pictures will appear in a gray square. Thus, they have a one in five or $20 \%$ probability of getting the picture correct by chance. The remote viewing averages were slightly above chance accuracy in the pre-survey (21\%) and slightly below chance in the post-survey (19\%).

\section{Research Question 3: What Workshop and Individual Characteristics Predict Changes in Outcomes?}

Workshop format. The workshop formats of lecture, small group, pairs, and discussion predicted changes in the well-being measures (Table 4). For example, a small group workshop format was associated with -5.39 points in the AIOS change score (post-pre) at fixed levels of the other formats (covariates). None of the workshop format or content variables predicted change in the three interconnectedness measures. Only the discussion format predicted the extended perception measure score changes $\left(X^{2}=24.54, p=0.0001\right.$; remote viewing change $(\beta-0.10, \mathrm{SE}-0.02)$, intuition change ( $\beta-53.69$, SE40.83), time estimation change ( $\beta-0.27$, SE-0.32), bubble change ( $\beta-0.04$, SE-0.01)).

Workshop content. Meditation and technology tools workshop content predicted well-being changes (Table 4). For example, meditation workshop content was associated with +3.61 points in the AIOS change score (post-pre) at fixed levels of the other formats (covariates). No other workshop content variables were significant for any other outcomes with multiple comparison corrections. Statistical output for the workshop characteristic models is in the Supplemental Data.

Demographics and mental and physical health. The age, gender, education, relationship, race, and income demographics variables did not predict any outcome variable. Only one of the mental and physical health variables predicted an outcome: the personality trait of conscientiousness predicted wellbeing outcomes, although the direction of association varied (Table 4). For example, conscientiousness was associated with decreased overall well-being scores (AIOS) but improved sleep disturbance and pain. For every one-point increase in conscientiousness score, there was a 3.35 decrease in overall well-being score change (AIOS), meaning there was less improvement after the workshop.

\section{Limitations}

Several limitations should be considered when reviewing these results. The study participants were self-selected and highly motivated in that they enrolled themselves in the personal development workshop. Participants could also take the surveys multiple times, sometimes taking the post-survey without a pre-survey. This study's data collection could be likened to an effectiveness study evaluating real-world implementation of personal development workshops rather than an efficacy study where measure collection is much more controlled. Thus, the study results are likely not generalizable to other populations who are not self-selected. Future studies interested in efficacy should include more stringent methods for measure collection and an incentive for participants to complete the measures before and after workshops. The study only collected post-surveys immediately after the workshops, and future research could evaluate if the effects are maintained over time. Some participants completed their workshop at the EarthRise Learning Center, and others did not, which may have influenced results. Future research could include this parameter as a covariate to see if it influenced the results. An uncontrolled prospective study design precludes knowing if outcome changes result from a natural progression of outcome changes in an individual over time, in the absence of any intervention. Without a control group, any pre- to post-changes could have resulted from taking 
time off from work, social interaction, or on-site participants benefitting from a natural retreat center setting. Workshop types and lengths were also highly variable ranging from a few hours to 10 months, which reduces confidence that the workshops were the sole agents in outcome changes. Our datasets also had missing data because participants could elect to skip a question. Methods to deal with missing data, such as multiple imputation, were not used to complete missing data. Some people took the same workshop multiple times, and because the statistical model did not include repeated measures, these data were not used. Finally, many of the measures within categories were correlated, and future studies could eliminate redundant measures or combine these into composite measures. Regardless of these limitations, this study has provided data for power calculations and guidance for refining methods and measures for future studies.

\section{Discussion}

This study found that the subjective sense of interconnectedness and well-being were positively correlated but that extended perception task performance was not. When looking at all the workshops together, personal development activities improved subjective interconnectedness, well-being, positive emotion, compassion, and reduced sleep disturbance, negative emotion, and pain.

Perhaps the act of engaging in personal growth activities, regardless of their specific focus, may improve a person's sense of meaning and purpose and their sense of connectedness with those around them. The impact social connectedness has on individuals' psychology is not merely an external feature that provides context for individual behavior but a capacity that can be internalized as a part of a person's social identity. Connectedness has positive psychological consequences associated with an individuals' sense of meaning, purpose, and belonging. ${ }^{35}$

Only one of the extended perception measures changed after the workshop and in the opposite direction than expected. Participants performed significantly worse on the remote viewing task after their workshops. Numerous studies have demonstrated this phenomenon's validity in trained and naïve individuals. ${ }^{36}$ However, it has long been noted that positive initial results in these kinds of tests can significantly reverse in follow-up tests, possibly due to unconscious fears that such abilities tend to evoke. ${ }^{37,38}$ Whether participant anxiety, unconscious fears, or other factors created worse task performance after the workshops is unknown. What is known is that none of the workshops were specifically designed to support or train these types of extended perceptions. Including these workshops in future studies will help clarify this finding. In any case, extended perception effects observed in the laboratory tend to be small and variable. Thus, the lack of significant changes in the other measures may simply reflect inadequate power in this study on these outcomes that will be addressed in subsequent studies.

The workshop format model revealed some interesting findings. If the workshop leader checked having a discussion format as part of their workshop, there were associated improvements in overall well-being, negative affect, and compassion, although positive affect, sleep disturbance, and pain were not. The lecture and small group formats were associated with less improvement in five out of the six well-being measures, and the pairs format was associated with less improvement in four of the six well-being measures. The other workshop formats, outside in nature and movement, were not significant predictors in the model. These results suggest that more engaging workshop formats might result in more remarkable improvement in wellbeing measures. Perhaps the formats of didactic lectures, small group, or paired activities do not require as much participant investment and have less transformative potential. These speculations could be further explored by understanding each format's percentage within the workshop and having more workshops for each format in future studies.

Meditation as a workshop component was the most consistent predictor associated with expected positive changes in well-being. Growing evidence has demonstrated meditation's positive benefits in multiple populations, especially in stress and pain reduction and quality of life. ${ }^{39}$ This result suggests that including some aspects of meditation in workshops may be beneficial regardless of their specific focus. However, it should be noted that data on the specific type of meditation used (e.g., concentrative, mindfulness, transcendental) was not collected from the workshop leaders. Workshop leaders only designated whether they did or did not include meditation in their workshops. Therefore, we cannot say what type of meditation may be associated with well-being improvement. Future research could include these measures to evaluate the nuances of meditation improving well-being as part of personal development workshops.

In general, individual characteristics like demographics or mental or physical health did not predict any outcomes. Only the personality trait of conscientiousness was a significant predictor for the well-being outcome measures, although with mixed directions of expected change (e.g., associated with lower overall well-being post-workshop scores but greater compassion post-workshop scores). Formal studies are needed to investigate these contrary findings.

This study collected preliminary data for three research questions: 1) What are the relationships, if any, between measures of well-being, interconnectedness, and extended perception? 2) What measure changes, if any, occur from before to after the workshops? and 3) What workshop and individual characteristics, if any, predict changes in outcomes? The data collected in this study allowed power calculations to be conducted for a formal analysis of these three research questions. The formal study and analyses have been pre-registered with the University of Edinburgh KPU Study Registry \#1057, and data is currently being collected.

\section{Conclusions}

This study provides preliminary evidence for a positive relationship between the subjective sense of interconnectedness and multiple well-being measures and the beneficial effects of some personal development workshops. Future research will formally evaluate the relationships between the three 
factors, outcome changes due to workshops, and predictors moderating these relationships.

\section{Declarations}

Acknowledgments: The authors would like to thank the Institute of Noetic Sciences (IONS) and its supporters, IONS Earthrise Campus Retreat Center staff, Cedric Cannard, Steven Swanson, Angel Vazquez, Monica Summers, Paolo Speirn, Julia Mossbridge, Loren Carpenter, Maria Wojakowski, the workshop leaders and participants for their contributions to this project.

Authorship Confirmation Statement: All authors made substantial contributions to the conception or design of the work; or the acquisition, analysis, or interpretation of data for the work; AND Drafted the work or revised it critically for important intellectual content; AND Gave final approval of the version to be published; AND Agree to be accountable for all aspects of the work in ensuring that questions related to the accuracy or integrity of any part of the work are appropriately investigated and resolved.

Helané Wahbeh - Conception or design of the work; acquisition, analysis, or interpretation of data for the work, and drafted and revised work critically for important intellectual content.

Garret Yount - Conception or design of the work, revised it critically for important intellectual content

Cassandra Vieten - Conception or design of the work, revised it critically for important intellectual content

Dean Radin - Conception or design of the work, revised it critically for important intellectual content

Arnaud Delorme - Conception or design of the work, acquisition, analysis, or interpretation of data for the work, and revised it critically for important intellectual content

Author Disclosure Statement: All authors have no financial disclosures or disclaimers to report.

Funding statement: The John Sperling Foundation, John Brockway Huntington Foundation and Patricia Beck Phillips Foundation supported this work.

Data Availability Statement: The data that support the findings of this study are available from the corresponding author, HW, upon reasonable request.

\section{References}

1. Grand View Research, Inc. Personal Development Market Size Report, 2020-2027. Published 2020. Accessed December 3, 2020.

https://www.grandviewresearch.com/industry-analysis/personal-development-market

2. OECD. OECD Guidelines on Measuring Subjective Well-being. In: The National Academies Collection: Reports funded by National Institutes of Health. OECD Publishing; 2013. doi:10.1787/9789264191655-en

3. Hernandez R, Bassett SM, Boughton SW, Schuette SA, Shiu EW, Moskowitz JT. Psychological Well-Being and Physical Health: Associations, Mechanisms, and Future Directions. Emotion Review. 2018;10(1):18-29. doi:10.1177/1754073917697824

4. Yu BCL, Mak WWS, Chio FHN. Promotion of Well-Being by Raising the Awareness on the Interdependent Nature of All Matters: Development and Validation of the Interconnectedness Scale. Mindfulness. 2020;11(5):1238-1252. doi:10.1007/s12671-020-01334-5

5. Wahbeh H, Sagher A, Back W, Pundhir P, Travis F. A Systematic Review of Transcendent States Across Meditation and Contemplative Traditions. Explore (NY). 2018;14(1):19-35. doi:10.1016/j.explore.2017.07.007

6. Radin DI, Vieten C, Michel L, Delorme A. Electrocortical activity prior to unpredictable stimuli in meditators and nonmeditators. Explore (NY). 2011;7(5):286-299. doi:10.1016/j.explore.2011.06.004

7. Vieten $\mathrm{C}$, Wahbeh $\mathrm{H}$, Cahn BR, et al. Future directions in meditation research: Recommendations for expanding the field of contemplative science. PLOS ONE. 2018;13(11):e0205740. doi:10.1371/journal.pone.0205740

8. Radin D, Ferrari D. Effects of consciousness on the fall of dice: A meta-analysis. Journal of Scientific Exploration. 1991;5(1):61-83.

9. Varvoglis M, Bancel PA. Micro-psychokinesis. In: Parapsychology: A Handbook for the 21st Century. McFarland \& Co; $2015: 266-281$.

10. Roe CA, Sonnex C, Roxburgh EC. Two meta-analyses of noncontact healing studies. EXPLORE: The Journal of Science and Healing. 2015;11(1):11-23.

11. Schmidt S, Schneider R, Utts J, Walach H. Distant intentionality and the feeling of being stared at: Two meta-analyses. British Journal of Psychology. 2004;95(2):235-247. 
12. Storm L, Tressoldi PE, Di Risio L. Meta-analysis of free-response studies, 1992-2008: assessing the noise reduction model in parapsychology. Psychological Bulletin. 2010;136(4):471-485. doi:10.1037/a0019457

13. May EC, Marwaha SB. The Star Gate Archives: Reports of the United States Government Sponsored Psi Program, 1972-1995. Vol 1. McFarland \& Company; 2018.

14. Kolodziejzyk G. Greg Kolodziejzyk's 13-year associative remote viewing experiment results. Journal of Parapsychology. 2013;76:349-368.

15. Mossbridge J, Radin D. Precognition as a form of prospection: A review of the evidence. Psychology of Consciousness: Theory, Research, and Practice. 2018;5(1):78.

16. Schwartz SA. The Location and Reconstruction of a Byzantine Structure in Marea, Egypt, Including a Comparison of Electronic Remote Sensing and Remote Viewing. Journal of Scientific Exploration. 2019;33(3):451-480.

17. Kennedy JE, Kanthamani H. An exploratory study of the effects of paranormal and spiritual experiences on peoples' lives and well-being. Journal of the American Society for Psychical Research. 1995;89(3):249-264.

18. Ellison CG, Fan D. Daily spiritual experiences and psychological well-being among US adults. Social Indicators Research. 2008;88(2):247-271.

19. Wahbeh H, Radin D, Mossbridge J, Vieten C, Delorme A. Exceptional experiences reported by scientists and engineers. Explore (New York, NY). 2018;14(5):329-341. doi:10.1016/j.explore.2018.05.002

20. Bell IR, Cunningham V, Caspi O, Meek P, Ferro L. Development and validation of a new global well-being outcomes rating scale for integrative medicine research. BMC Complement Altern Med. 2004;4:1. doi:10.1186/1472-6882-4-1

21. Jebb AT, Tay L, Diener E, Oishi S. Happiness, income satiation and turning points around the world. Nature Human Behaviour. 2018;2(1):33-38. doi:10.1038/s41562-017-0277-0

22. Shiota MN, Keltner D, John OP. Positive emotion dispositions differentially associated with Big Five personality and attachment style. The Journal of Positive Psychology. 2006;1(2):61-71.

23. Cappelleri JC, Bushmakin AG, McDermott AM, Sadosky AB, Petrie CD, Martin S. Psychometric properties of a single-item scale to assess sleep quality among individuals with fibromyalgia. Health Qual Life Outcomes. 2009;7:54. doi:10.1186/1477-7525-7-54

24. Farrar JT, Young JP, LaMoreaux L, Werth JL, Poole RM. Clinical importance of changes in chronic pain intensity measured on an 11-point numerical pain rating scale. Pain 11690728. 2001;94(2):149-158. doi:S0304-3959(01)00349-9 [pii]

25. Cloninger CR, Przybeck TR, Svrakic DM, Wetzel RD. The Temperament and Character Inventory (TCI): A Guide to Its Development and Use. Center for Psychobiology of Personality, Washington University; 1994.

26. Schultz PW. Inclusion with nature: The psychology of human-nature relations. In: Psychology of Sustainable Development. Springer; 2002:61-78.

27. Schultz PW, Shriver C, Tabanico JJ, Khazian AM. Implicit connections with nature. Journal of Environmental Psychology. 2004;24(1):31-42. doi:10.1016/S0272-4944(03)00022-7

28. Aron A, Aron EN, Tudor M, Nelson G. Close relationships as including other in the self. Journal of personality and social psychology. $1991 ; 60(2): 241$.

29. Aron A, Aron EN, Smollan D. Inclusion of other in the self scale and the structure of interpersonal closeness. Journal of personality and social psychology. 1992;63(4):596.

30. DeSalvo KB, Bloser N, Reynolds K, He J, Muntner P. Mortality Prediction with a Single General Self-Rated Health Question. J Gen Intern Med. 2006;21(3):267-275. doi:10.1111/j.1525-1497.2005.00291.x

31. Rammstedt B. The 10-item Big Five Inventory: Norm values and investigation of sociodemographic effects based on a German population representative sample. European Journal of Psychological Assessment. 2007;23(3):193.

32. Wahbeh H, Yount G, Vieten C, Radin D, Delorme A. Measuring extraordinary experiences and beliefs: A validation and reliability study [version 3; peer review: 3 approved]. F1000Research. 2020;8(1741):29. doi:https://doi.org/10.12688/f1000research.20409.3

33. Nordhausen K, Oja H. Multivariate L1 methods: the package MNM. Journal of Statistical Software. 2011;43(5):1-28.

34. Benjamini Y, Hochberg Y. Controlling the false discovery rate: A practical and powerful approach to multiple testing. Journal of the Royal Statistical Society Series B (Methodological). 1995;57(1):289-300. 
35. Haslam SA, Jetten J, Postmes T, Haslam C. Social identity, health and well-being: An emerging agenda for applied psychology. Applied psychology: an international review. 2009;58(1):1-23.

36. Targ R. What Do We Know about Psi? The First Decade of Remote-Viewing Research and Operations at Stanford Research Institute. Journal of Scientific Exploration. 2019;33(4):569-592.

37. Eisenbud J. Parapsychology and the Unconscious. SO: Berkeley, CA: North Atlantic Books, 1983. Published online 1983.

38. Rhine J. The problem of psi-missing. The Journal of Parapsychology. 1952;16(2):90.

39. Goyal M, Singh S, Sibinga EM, et al. Meditation Programs for Psychological Stress and Well-being: A Systematic Review and Meta-analysis. JAMA Intern Med. Published online January 6, 2014. doi:10.1001/jamainternmed.2013.13018 1809754 [pii]

1. Grand View Research, Inc. Personal Development Market Size Report, 2020-2027. Published 2020. Accessed December 3, 2020. https://www.grandviewresearch.com/industry-analysis/personal-development-market

2. OECD. OECD Guidelines on Measuring Subjective Well-being. In: The National Academies Collection: Reports funded by National Institutes of Health. OECD Publishing; 2013. doi:10.1787/9789264191655-en

3. Hernandez R, Bassett SM, Boughton SW, Schuette SA, Shiu EW, Moskowitz JT. Psychological Well-Being and Physical Health: Associations, Mechanisms, and Future Directions. Emotion Review. 2018;10(1):18-29. doi:10.1177/1754073917697824

4. Yu BCL, Mak WWS, Chio FHN. Promotion of Well-Being by Raising the Awareness on the Interdependent Nature of All Matters: Development and Validation of the Interconnectedness Scale. Mindfulness. 2020;11(5):1238-1252. doi:10.1007/s12671-020-01334-5

5. Wahbeh H, Sagher A, Back W, Pundhir P, Travis F. A Systematic Review of Transcendent States Across Meditation and Contemplative Traditions. Explore (NY). 2018;14(1):19-35. doi:10.1016/j.explore.2017.07.007

6. Dean I. Radin, Cassandra Vieten, Leena Michel, Arnaud Delorme. Electrocortical activity prior to unpredictable stimuli in meditators and nonmeditators. Explore. 2011;7:286-299.

7. Vieten $\mathrm{C}$, Wahbeh $\mathrm{H}, \mathrm{Cahn} \mathrm{BR}$, et al. Future directions in meditation research: Recommendations for expanding the field of contemplative science. PLOS ONE. 2018;13(11):e0205740. doi:10.1371/journal.pone.0205740

8. Radin D, Ferrari D. Effects of consciousness on the fall of dice: A meta-analysis. Journal of Scientific Exploration. 1991;5(1):61-83.

9. Varvoglis M, Bancel PA. Micro-psychokinesis. In: Parapsychology: A Handbook for the 21st Century. McFarland \& Co; 2015:266-281.

10. Roe CA, Sonnex C, Roxburgh EC. Two meta-analyses of noncontact healing studies. EXPLORE: The Journal of Science and Healing. $2015 ; 11(1): 11-23$.

11. Schmidt S, Schneider R, Utts J, Walach H. Distant intentionality and the feeling of being stared at: Two meta-analyses. British Journal of Psychology. 2004;95(2):235-247.

12. Storm L, Tressoldi PE, Di Risio L. Meta-analysis of free-response studies, 1992-2008: assessing the noise reduction model in parapsychology. Psychological Bulletin. 2010;136(4):471-485. doi:10.1037/a0019457

13. May EC, Marwaha SB. The Star Gate Archives: Reports of the United States Government Sponsored Psi Program, 1972-1995. Vol 1. McFarland \& Company; 2018.

14. Kolodziejzyk G. Greg Kolodziejzyk's 13-year associative remote viewing experiment results. Journal of Parapsychology. 2013;76:349-368.

15. Mossbridge J, Radin D. Precognition as a form of prospection: A review of the evidence. Psychology of Consciousness: Theory, Research, and Practice. 2018;5(1):78.

16. Schwartz SA. The Location and Reconstruction of a Byzantine Structure in Marea, Egypt, Including a Comparison of Electronic Remote Sensing and Remote Viewing. Journal of Scientific Exploration. 2019;33(3):451-480.

17. Bell IR, Cunningham V, Caspi O, Meek P, Ferro L. Development and validation of a new global well-being outcomes rating scale for integrative medicine research. BMC Complement Altern Med. 2004;4:1. doi:10.1186/1472-6882-4-1

18. Jebb AT, Tay L, Diener E, Oishi S. Happiness, income satiation and turning points around the world. Nature Human Behaviour. 2018;2(1):33-38. doi:10.1038/s41562-017-0277-0

19. Shiota MN, Keltner D, John OP. Positive emotion dispositions differentially associated with Big Five personality and attachment style. The Journal of Positive Psychology. 2006;1(2):61-71. 
20. Cappelleri JC, Bushmakin AG, McDermott AM, Sadosky AB, Petrie CD, Martin S. Psychometric properties of a single-item scale to assess sleep quality among individuals with fibromyalgia. Health Qual Life Outcomes. 2009;7:54. doi:10.1186/1477-7525-7-54

21. Farrar JT, Young JP, LaMoreaux L, Werth JL, Poole RM. Clinical importance of changes in chronic pain intensity measured on an 11-point numerical pain rating scale. Pain 11690728. 2001;94(2):149-158. doi:S0304-3959(01)00349-9 [pii]

22. Cloninger CR, Przybeck TR, Svrakic DM, Wetzel RD. The Temperament and Character Inventory (TCI): A Guide to Its Development and Use. Center for Psychobiology of Personality, Washington University; 1994.

23. Schultz PW. Inclusion with nature: The psychology of human-nature relations. In: Psychology of Sustainable Development. Springer; 2002:61-78.

24. Schultz PW, Shriver C, Tabanico JJ, Khazian AM. Implicit connections with nature. Journal of Environmental Psychology. 2004;24(1):31-42.

doi:10.1016/S0272-4944(03)00022-7

25. Aron A, Aron EN, Tudor M, Nelson G. Close relationships as including other in the self. Journal of personality and social psychology. $1991 ; 60(2): 241$.

26. Aron A, Aron EN, Smollan D. Inclusion of other in the self scale and the structure of interpersonal closeness. Journal of personality and social psychology. 1992;63(4):596.

27. DeSalvo KB, Bloser N, Reynolds K, He J, Muntner P. Mortality Prediction with a Single General Self-Rated Health Question. J Gen Intern Med. 2006;21(3):267-275. doi:10.1111/j.1525-1497.2005.00291.x

28. Rammstedt B. The 10-item Big Five Inventory: Norm values and investigation of sociodemographic effects based on a German population representative sample. European Journal of Psychological Assessment. 2007;23(3):193.

29. Wahbeh H, Yount G, Vieten C, Radin D, Delorme A. Measuring extraordinary experiences and beliefs: A validation and reliability study [version 3; peer review: 3 approved]. F1000Research. 2020;8(1741):29. doi:https://doi.org/10.12688/f1000research.20409.3

30. Nordhausen K, Oja H. Multivariate L1 methods: the package MNM. Journal of Statistical Software. 2011;43(5):1-28.

31. Benjamini Y, Hochberg Y. Controlling the false discovery rate: A practical and powerful approach to multiple testing. Journal of the Royal Statistical Society Series B (Methodological). 1995;57(1):289-300.

32. Haslam SA, Jetten J, Postmes T, Haslam C. Social identity, health and well-being: An emerging agenda for applied psychology. Applied psychology: an international review. 2009;58(1):1-23.

33. Targ R. What Do We Know about Psi? The First Decade of Remote-Viewing Research and Operations at Stanford Research Institute. Journal of Scientific Exploration. 2019;33(4):569-592.

34. Eisenbud J. Parapsychology and the Unconscious. SO: Berkeley, CA: North Atlantic Books, 1983. Published online 1983.

35. Rhine J. The problem of psi-missing. The Journal of Parapsychology. 1952;16(2):90.

36. Goyal M, Singh S, Sibinga EM, et al. Meditation Programs for Psychological Stress and Well-being: A Systematic Review and Meta-analysis. JAMA Intern Med. Published online January 6, 2014. doi:10.1001/jamainternmed.2013.13018 1809754 [pii]

\section{Tables}

Table 1

Participant's demographic information 


\begin{tabular}{|c|c|c|c|c|c|c|c|}
\hline & & PRE-Only & & & PRE-POST & & \\
\hline Measure & Category & $A v g \pm S D$ & $\%$ & $\mathbf{N}$ & Avg $\pm S D$ & $\%$ & $\mathbf{N}$ \\
\hline Age & Years & $56.2 \pm 13.3$ & & 1156 & $55.2 \pm 13.0$ & & 521 \\
\hline Education & Years & $17.3 \pm 3.0$ & & 1155 & $17.0 \pm 2.8$ & & 514 \\
\hline \multirow[t]{3}{*}{ Gender } & Male & 875 & 75.9 & 1153 & 402 & 77.2 & 521 \\
\hline & Female & 271 & 23.5 & & 117 & 22.5 & \\
\hline & Other & 7 & 0.6 & & 2 & 0.4 & \\
\hline \multirow[t]{6}{*}{ Race } & American Indian & 12 & 1.0 & 1154 & 5 & 1.0 & 513 \\
\hline & Asian/Pacific Islander & 67 & 5.8 & & 30 & 5.8 & \\
\hline & Black or African American & 26 & 2.3 & & 8 & 1.6 & \\
\hline & Hispanic & 52 & 4.5 & & 21 & 4.1 & \\
\hline & White/Caucasian & 963 & 2.95 & & 432 & 84.2 & \\
\hline & Other & 34 & 83.5 & & 17 & 3.3 & \\
\hline \multirow[t]{2}{*}{ Relationship } & In a relationship & 426 & 37.5 & 1137 & 303 & 39.8 & 503 \\
\hline & Not in a relationship & 711 & 62.5 & & 200 & 60.2 & \\
\hline \multirow[t]{3}{*}{ Income } & $\$ 150 \mathrm{~K}$ and above & 253 & 24.4 & 1034 & 104 & 22.5 & 462 \\
\hline & $\$ 75 \mathrm{~K}$ to under $\$ 150 \mathrm{~K}$ & 407 & 39.2 & & 186 & 40.3 & \\
\hline & 0 to under $\$ 75 \mathrm{~K}$ & 374 & 36.0 & & 172 & 37.2 & \\
\hline Hsehld Num & & $2.2 \pm 1.3$ & & 1142 & $2.2 \pm 1.3$ & & 506 \\
\hline \multirow[t]{3}{*}{ Setting } & Rural & 220 & 19.2 & 1147 & 116 & 22.8 & 509 \\
\hline & Suburban & 541 & 47.2 & & 246 & 48.3 & \\
\hline & Urban & 386 & 33.7 & & 147 & 28.9 & \\
\hline \multirow[t]{5}{*}{ Overall Health } & Poor & 3 & 0.3 & 1149 & 0 & 0 & 511 \\
\hline & Fair & 128 & 11.1 & & 72 & 14.1 & \\
\hline & Good & 403 & 35.1 & & 168 & 32.9 & \\
\hline & Very good & 478 & 41.6 & & 221 & 43.3 & \\
\hline & Excellent & 137 & 11.9 & & 50 & 9.8 & \\
\hline \multirow[t]{5}{*}{ Spiritual affiliation childhood } & Not religious or spiritual & 184 & 16.0 & 1152 & 89 & 17.4 & 513 \\
\hline & Non-practicing religious & 53 & 4.6 & & 20 & 3.9 & \\
\hline & Minimally practicing religious & 333 & 28.9 & & 153 & 29.8 & \\
\hline & Practicing religious & 530 & 46.0 & & 224 & 43.7 & \\
\hline & Spiritual but not religious & 52 & 4.5 & & 27 & 5.3 & \\
\hline \multirow[t]{5}{*}{ Spiritual affiliation current } & Not religious or spiritual & 57 & 5.0 & 1144 & 22 & 4.3 & 510 \\
\hline & Non-practicing religious & 34 & 3.0 & & 20 & 3.9 & \\
\hline & Minimally practicing religious & 69 & 6.0 & & 29 & 5.7 & \\
\hline & Practicing religious & 83 & 7.3 & & 32 & 6.3 & \\
\hline & Spiritual but not religious & 901 & 78.8 & & 407 & 79.8 & \\
\hline Meditators & Yes & 881 & 76.9 & 1146 & 382 & 74.9 & 510 \\
\hline
\end{tabular}

Table 2 


\begin{tabular}{|c|c|c|c|c|c|c|c|c|c|c|c|c|c|c|c|}
\hline & $\mathbf{N}$ & $\begin{array}{l}\text { Mean } \\
\text { (SD) }\end{array}$ & Int & $\begin{array}{l}\text { Int } \\
\text { Others }\end{array}$ & $\begin{array}{l}\text { Int } \\
\text { Nature }\end{array}$ & Intuition & Time & RV & Bubble & AlOS & PA & NA & Comp & SIp_24 & Pn_24 \\
\hline Int & 1,137 & $\begin{array}{l}10.5 \\
(2.8)\end{array}$ & 1 & & & & & & & & & & & & \\
\hline $\begin{array}{l}\text { Int } \\
\text { Others }\end{array}$ & 1,054 & $\begin{array}{l}63.1 \\
(22.4)\end{array}$ & $\underline{0.35}$ & 1 & & & & & & & & & & & \\
\hline $\begin{array}{l}\text { Int } \\
\text { Nature }\end{array}$ & 1,111 & $\begin{array}{l}73 \\
(20.7)\end{array}$ & $\underline{0.43}$ & $\underline{0.39}$ & 1 & & & & & & & & & & \\
\hline Intuition & 1,062 & $\begin{array}{l}237.4 \\
(337.3)\end{array}$ & 0.06 & 0.08 & 0.02 & 1 & & & & & & & & & \\
\hline Time & 1,067 & $\begin{array}{l}2.4 \\
(2.3)\end{array}$ & 0.03 & 0.05 & 0.03 & 0.03 & 1 & & & & & & & & \\
\hline RV & 1,062 & $\begin{array}{l}0.2 \\
(0.1)\end{array}$ & -0.06 & -0.06 & -0.02 & 0.02 & -0.02 & 1 & & & & & & & \\
\hline Bubble & 1,071 & $\begin{array}{l}0.08 \\
(0.06)\end{array}$ & 0.04 & 0.02 & 0.03 & 0.03 & 0.02 & 0.01 & 1 & & & & & & \\
\hline AlOS & 1,096 & $\begin{array}{l}63.4 \\
(19.9)\end{array}$ & $\underline{0.33}$ & $\underline{0.34}$ & $\underline{0.27}$ & 0.01 & -0.05 & -0.03 & 0.04 & 1 & & & & & \\
\hline PA & 1,145 & $\begin{array}{l}0.8 \\
(0.3)\end{array}$ & $\underline{0.25}$ & $\underline{0.27}$ & $\underline{0.20}$ & 0 & 0.02 & -0.05 & 0.06 & $\underline{0.44}$ & 1 & & & & \\
\hline NA & 1,134 & $\begin{array}{l}0.5 \\
(0.4)\end{array}$ & -0.08 & -0.19 & -0.12 & 0 & 0.04 & 0.01 & -0.01 & $\underline{-0.42}$ & $\underline{-0.18}$ & 1 & & & \\
\hline Comp & 1,153 & $5.7(1)$ & $\underline{0.32}$ & $\underline{0.29}$ & $\underline{0.21}$ & 0.06 & 0.02 & -0.06 & 0.02 & $\underline{0.13}$ & $\underline{0.14}$ & -0.01 & 1 & & \\
\hline SIp-24 & 1,110 & $\begin{array}{l}4.1 \\
(2.4)\end{array}$ & $\underline{-0.16}$ & -0.15 & -0.13 & -0.04 & 0.03 & 0.03 & -0.01 & -0.41 & $\underline{-0.21}$ & $\underline{0.22}$ & -0.08 & 1 & \\
\hline Pn-24 & 1,122 & $\begin{array}{l}3.1 \\
(2.7)\end{array}$ & -0.16 & -0.11 & -0.11 & -0.02 & 0.03 & 0.03 & -0.01 & -0.37 & -0.15 & $\underline{0.19}$ & -0.10 & $\underline{0.28}$ & 1 \\
\hline
\end{tabular}

Note: Participant number is in column 2. Mean and standard deviations are in column 3. Spearman's $\rho$ correlation coefficients are desplayed for each correlation. The font of the Spearman $\rho$ designates $p$-value: 1) regular font denotes 'not significant' according to the FDR corrected $p$-value level of 0.0428 (i.e., regular font $p>0.0428$ ); bold font are significant, with $p$-values $<0.0428$; bold and underlined font are significant, with $p$-values $<0.00005$. Participant numbers for each correlation and exact $p$-values are included in Supplemental Data. Int - Cloninger Self-Transcendence scale, Int Others Interconnectedness with Others, Int Nature - Interconnectedness with Nature, Intuition - Jar Task, Time - Time Estimation task, RV - Remote Viewing Task, Bubble - Bubble psychokinesis task, AIOS - Arizona Integrative Outcomes Scale overall well-being, PA - Positive Affect, NA - Negative Affect, Comp - Compassion, SIp_24 - sleep disturbance in the last 24 hours, Pn_24 - pain in the last 24 hours.

Table 3

Paired pre-post outcome values and comparisons 


\begin{tabular}{|c|c|c|c|}
\hline & Pre & Post & Wilcoxon Signed-Rank Test \\
\hline Measure & Mean (SD) & Mean (SD) & $z$, p-value \\
\hline \multicolumn{4}{|l|}{ Well-being } \\
\hline AIOS (0-100; 100 best) & $61.8(19.3)$ & $68.4(17.9)$ & $6.83,<0.00005^{\star}$ \\
\hline PA (0-1.0; 1.0 most positive) & $0.8(0.3)$ & $0.9(0.3)$ & $4.15,<0.00005^{\star}$ \\
\hline NA (0-1.0; 1.0 most negative) & $0.5(0.4)$ & $0.4(0.4)$ & $-6.38,<0.00005^{\star}$ \\
\hline Compassion (0-7; 7 most compassion) & $5.7(0.8)$ & $5.9(1.1)$ & $7.21,<0.00005^{\star}$ \\
\hline Sleep disturbance last night ( $0-10 ; 0$ best) & $4.1(2.4)$ & $3.4(2.4)$ & $-6.52,<0.00005^{\star}$ \\
\hline Pain last 24 hours (0-10; 0 none) & $3.2(2.6)$ & $2.6(2.4)$ & $-6.43,<0.00005^{\star}$ \\
\hline \multicolumn{4}{|l|}{ Interconnectedness } \\
\hline Self-transcendence $(0-15,15$ best $)$ & $10.4(2.7)$ & $10.9(2.6)$ & $6.44,<0.00005^{\star}$ \\
\hline With nature $(0-100,100$ best $)$ & $71.6(21.4)$ & 77.7 (17.5) & $7.44,<0.00005^{\star}$ \\
\hline With others ( $0-100,100$ best) & $62.9(22.4)$ & $69.3(21.4)$ & $6.12,<0.00005^{\star}$ \\
\hline \multicolumn{4}{|l|}{ Extended Perception } \\
\hline Intuition abs & $221.9(219.7)$ & $245.8(260.8)$ & $1.31,0.19$ \\
\hline Time estimation abs & $2.4(2.5)$ & $2.4(2.3)$ & $-0.64,0.52$ \\
\hline Remote viewing & $0.21(0.13)$ & $0.19(0.12)$ & $-2.76,0.006^{\star}$ \\
\hline Bubble task abs & $0.0795(0.0590)$ & $0.0815(0.0643)$ & $-0.29,0.77$ \\
\hline
\end{tabular}

Note. * $p$-values $\leq 0.006$ are significant with False Discovery Rate multiple comparison correction (13 comparisons, $p=0.05)$. AlOS - Arizona Integrative Outcomes Scale, PA - Positive Affect, NA - Negative Affect, abs - absolute value.

Table 4

Significant Predictors for well-being outcome changes

\begin{tabular}{|lllllllll|}
\hline Predictor & AIOS & PA & NA & Compassion & Sleep change & Pain change & $X^{2}$ & $p$ \\
change & change & change & change & & & & \\
\hline Lecture & $-0.48(2.14)$ & $-0.01(0.03)$ & $0.01(0.05)$ & $-0.04(0.07)$ & $-0.76(0.30)$ & $0.53(0.23)$ & 13.71 & $0.03^{*}$ \\
\hline Small Groups & $-5.39(2.83)$ & $-0.03(0.03)$ & $0.21(0.06)$ & $0.06(0.10)$ & $1.13(0.39)$ & $0.05(0.30)$ & 22.45 & $0.001^{*}$ \\
\hline Pairs & $-3.86(2.34)$ & $-0.06(0.03)$ & $0.07(0.05)$ & $0.13(0.08)$ & $0.17(0.32)$ & $-0.79(0.25)$ & 17.95 & $0.01^{*}$ \\
\hline Discussion & $1.58(2.69)$ & $-0.02(0.03)$ & $-0.20(0.06)$ & $0.02(0.09)$ & $0.06(0.37)$ & $0.04(0.29)$ & 13.79 & $0.03^{*}$ \\
\hline Meditation & $3.61(2.27)$ & $0.05(0.03)$ & $-0.12(0.05)$ & $-0.05(0.08)$ & $-1.71(0.31)$ & $-0.07(0.26)$ & 26.09 & $0.0002^{*}$ \\
\hline Technology Tools & $-6.23(3.80)$ & $0.03(0.05)$ & $0.13(0.08)$ & $-0.33(0.13)$ & $0.67(0.52)$ & $0.90(0.43)$ & 17.83 & $0.01^{*}$ \\
\hline Conscientiousness & $-3.35(1.06)$ & $0.01(0.01)$ & $0.002(0.02)$ & $0.09(0.04)$ & $-0.09(0.15)$ & $-0.05(0.12)$ & 20.45 & $0.002^{*}$ \\
\hline
\end{tabular}

Note. This table presents the significant predictors from multiple models. Columns 2-7 contain the beta coefficient and standard error for that predictor. The complete statistical output is presented in Supplemental Data. PA = Positive Affect; NA = Negative Affect; AIOS = Arizona Integrative Outcomes Scale; Sleep = Sleep disturbance; $X^{2}=$ Chi-Square; $p=p$-value. *significant with FDR multiple comparison corrections. Shaded cells represent outcome change in the direction of improvement.

\section{Supplementary Files}

This is a list of supplementary files associated with this preprint. Click to download.

- SupplementalData.docx 